\title{
Microstructure Evaluation of Vaporizing Foil Actuator Welds of 1 GPa Strength Steel
}

\author{
Byoung-Hyun Yoon*, $\dagger$ and Taeseon Lee** \\ *Chungnam National University, Daejeon, 34134, Korea \\ **Department of materials science and engineering, Ohio State University, OH 43210, Columbus, USA
}

†Corresponding author : byoon007@naver.com

(Received June 24, 2020 ; Revised July 14, 2020 ; Accepted July 20, 2020)

\begin{abstract}
Demands for weight reduction in automobiles have been constantly increasing due to its environmental impact, leading to increased interests in light metals such as aluminum and magnesium. However, for most structural applications that require large energy absorption, implementation of high strength steel is still a pervasive solution.

When the high strength steel having a high martensite fraction (DP 980) is joined by resistance spot welding, a softening zone is generated in the welds, leading to the reduction of the strength of the welds. In addition, high strength steels generally contain a large amount of carbon and alloying elements. As a result, the carbon equivalent exhibiting hardenability increases, having the welded part become weak, and making it difficult to secure the performance required by the part or the vehicle body.

Vaporizing foil actuator welding (VFAW) which is one of the solid-state welding techniques utilizes a high-pressure pulse generated by the vaporization of an aluminum foil to cause high speed collision of flyer and target sheets to create solid-state bonds with negligible melting at the weld interface. So, VFAW produces joints with little to no HAZ.

In this study, to examine the vaporizing foil actuator welding properties of $1 \mathrm{GPa}$ grade high strength steel, microstructure analysis and hardness test were performed. The test results were compared with the resistance spot welding properties of the same material.
\end{abstract}

Key Words : $1 \mathrm{GPa}$ grade steel, Vaporizing foil actuator welding, Mechanical properties, Microstructure

\section{Introduction}

In the automotive industry, due to the strong demand for lighter body weight and improved collision stability, the applied material is increasingly strengthened, and the application of steel with a tensile strength of 1000 MPa has become greater. However, inferior weldability is an obstacle against applying ultra-high strength steel for automotive parts. In order to obtain a high strength, a large amount of carbon (about $0.1 \mathrm{wt} \% \mathrm{C}$ ) and alloying elements are generally added. As a result, the carbon equivalent exhibiting hardenability increases, so that the joint becomes brittle, and thus it becomes difficult to secure the performance required by the part or the vehicle ${ }^{1,2)}$.
In general, resistance spot welding is widely used for manufacturing automotive parts. However, the high-strength steel with a high carbon composition normally induces brittleness to the weld, which results in a low cross tensile strength. Especially, when high-strength steel with high martensite fraction (DP 780 steel, DP 980 steel, etc.) is welded on the electric resistance spot, the martensite of the base metal is heated to a temperature below the A1 transformation point (eutectoid transformation) by the heat of welding and is transformed into tempered martensite. So, a softening zone is generated, and fracture occurs in this area, thereby reducing the strength of the weld ${ }^{1}$. In order to solve this problem, efforts have recently been made to improve the welding strength of high strength steel through mechanical joining methods such as blind riveting or a hybrid welding method that 
simultaneously applies structural adhesive and spot welding $^{3-5)}$. Many automakers prefer welding processes that are more productive and economical, so it is necessary to consider simpler methods than hybrid welding that consists of two processes or riveting that requires additional elements. Thus, research on solid-state welding processes such as electromagnetic pulse welding or vaporizing foil actuator welding (VFAW) is being considered as an alternative ${ }^{6)}$.

Magnetic pulse welding (MPW $)^{7-11)}$ is a process that uses the same physical principles of explosive welding (EXW); a flyer material is rapidly driven towards a target to cause an impact, so that the surface oxides are removed by jetting ${ }^{12)}$. Although the bonding mechanism of MPW is not yet fully understood, most studies clearly observe the wavy interface shape as a representative feature $^{2)}$. The formation mechanisms of the wavy interface have been widely studied up to these days and is referred to extensively ${ }^{13}$.

Lee et al. ${ }^{14)}$ investigated the microstructural changes of dual phase (DP) steel during friction stir welding (FSW). In this study, friction-stir welded specimens of a butt joint configuration were prepared, and quasi-static tensile tests were performed to evaluate the mechanical properties. Friction stir welding resulted in a significant hardness increase by the formation of martensite in the stirring zone (SZ), but the presence of soft areas in the heat-affected zone (HAZ) was caused by tempering of the existing martensite. With the appearance of the soft zones, the DP980 FSW joint showed a joint efficiency of almost $93 \%$ in terms of tensile strength, but it also showed relatively low ductility compared to the base metal $(\mathrm{BM})^{14)}$. That is, FSW joints report reduced the overall ductility.

Kapil et al. ${ }^{6}$ reported that JSC590R was spot welded by VFAW. VFAW is relatively a new processing technology that uses similar physical principles of MPW, but the pressure is created by the vaporization of a thin conductor instead of an electromagnetic force. The development of the technique and its apparatus have been presented in previous researches ${ }^{6)}$ and will not be repeated in this paper. They claim that the VFAW joint exhibits excellent mechanical and fatigue properties while using lesser energy input than RSW.

This study focuses on the mechanical performance and microstructural evaluation of DP980-DP980 VFAW welds. The $1 \mathrm{GPa}$ grade steel was welded by VFAW and RSW, then metallurgical and mechanical characteristics were evaluated. The relationship between the microstructure and the hardness behavior of DP 980 welds was examined.

\section{Experimental Procedure}

\subsection{Base metal}

A DP 980 steel of a $1.2 \mathrm{~mm}$ thickness was used in this study. Chemical composition of the material is displayed in Table 1. The microstructure consists of a dual phase structure of ferrite matrix and martensite islands. The mechanical properties of the material are displayed in Table 2 (Provided by supplier).

\subsection{Welding preparation}

To examine the effects of the welding process on the microstructure and the strength, resistance spot welding and vaporizing foil actuators welding were performed. Fig. 1 demonstrates the experimental configuration of the vaporizing foil actuator welding. The input energy used in the capacitor bank was $8 \mathrm{~kJ}$.

A schematic of the VFAW process used in this study is demonstrated in Fig. 2a. To weld with VFAW, the flyer must be away from the target to be accelerated. The spacing between the flyer material and the target material is maintained by inserting a rectangular metal ( $2 \mathrm{~mm}$ thick) between the materials. The foil shape to be vaporized yields higher pressure in the narrow part of the foil (active area) as displayed in Fig. 2b. The foil

Table 1 A chemical composition of used material (provided by supplier)

\begin{tabular}{|c|c|c|c|c|c|c|}
\hline$(\mathrm{wt} \%)$ & $\mathrm{C}$ & $\mathrm{Si}$ & $\mathrm{Mn}$ & $\mathrm{P}$ & $\mathrm{S}$ & $\mathrm{Fe}$ \\
\hline DP980 & 0.1 & 0.1 & 2.5 & 0.011 & 0.03 & Bal. \\
\hline
\end{tabular}

Table 2 A mechanical properties of used material (provided by supplier)

\begin{tabular}{|c|c|c|c|}
\hline $\begin{array}{c}\text { Thickness } \\
(\mathrm{mm})\end{array}$ & $\begin{array}{c}\text { Yield strength } \\
(\mathrm{MPa})\end{array}$ & $\begin{array}{c}\text { Tensile strength } \\
(\mathrm{MPa})\end{array}$ & $\begin{array}{c}\text { Elongation } \\
(\%)\end{array}$ \\
\hline 1.2 & 846 & 1,035 & 11 \\
\hline
\end{tabular}

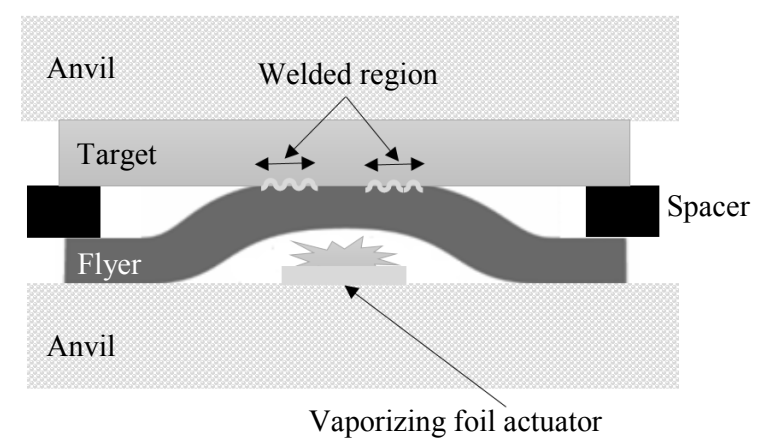

Fig. 1 Vaporizing foil actuator welding process 


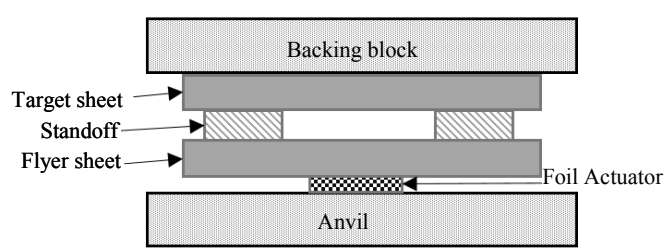

(a)

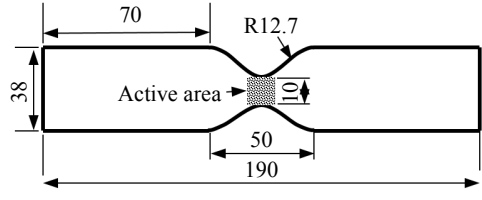

(b)

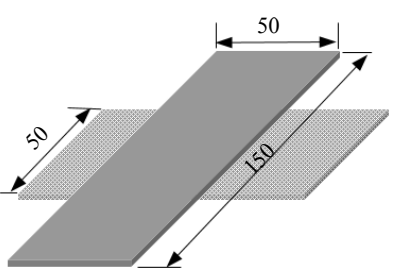

(c)

Fig. 2 Schematic arrangement of test specimen of the VFAW (Unit: mm) (a) Set-up jig, (b) Specification of aluminium foil actuator, (c) Joining test specimen

Table 3 A RSW welding conditions of used material

\begin{tabular}{|l|c|}
\hline \multicolumn{1}{|c|}{ Welding parameters } & Results \\
\hline Electrode force $(\mathrm{kN})$ & 5 \\
\hline Welding Current $(\mathrm{kA})$ & 7 \\
\hline Weld Time (Cycle) & 17 \\
\hline Squeeze Time (Cycle) & 20 \\
\hline Hold Time (Cycle) & 17 \\
\hline Electrode Diameter $(\mathrm{mm})$ & $\Phi 6(16 \mathrm{D})$ \\
\hline
\end{tabular}

consists of a thin bridge-type aluminum foil with a thickness of $0.0762 \mathrm{~mm}$ and an effective width of 10.16 $\mathrm{mm}$. The material is AA1145. The foil was electrically insulated from the fixture and the workpiece by polyester tape. The end of the actuator was connected to the output electrical leads of the capacitor bank and the flyer was concentrated on the narrow part of the foil. The capacitor bank used in this experiment can supply $16 \mathrm{~kJ}$ of electrical energy when charged to a voltage of up to $8.66 \mathrm{kV}$.

Specimens used for joining test were cross type with the dimensions depicted in Fig. 2c. Resistance spot welds (DP980 and DP980 pairs) and VFAW spot welds (DP980 and DP980 pair) were prepared using $50 \mathrm{~mm}$ wide samples for the microstructure and hardness evaluation.

For welding, a pneumatic AC resistance spot welder was used, and the electrode was made of a $\mathrm{Cu}-\mathrm{Cr}$ alloy-based dome-shaped electrode having a $6 \mathrm{~mm}$ tip diameter. The specimens were cut into $50 \mathrm{~mm}$ in width and $150 \mathrm{~mm}$ in length as shown in Fig. 2c. The surfaces were cleaned with ethanol and then overlap welded. Table 3 demonstrates the welding conditions. The welding current, welding time and holding time are fixed at the welding conditions recommended in ISO 18278-210. The pressing force was in $5 \mathrm{kN}$.

\subsection{Hardness test}

Hardness measurement was performed using a Micro Vickers hardness tester manufactured by Mitutoyo. The load was measured at $200 \mu \mathrm{m}$ intervals with a load of 300 gf in a diagonal direction at RSW welds and a perpendicular direction at VFAW welds. Holding time was 15 seconds.

\subsection{Microstructure evaluation}

The microstructures in the welds were observed with optical microscopy, scanning electron microscopy (SEM) and transmission electron microscopy (TEM). The sample was polished and etched by $3 \%$ nital solution. X-ray energy-dispersive spectroscopy (EDX) was also used for the compositional analysis. To conduct analysis of TEM, specimens was made by focused ion beam (FIB) and analyzed the ferrite, martensite and dislocation by Cs-corrected scanning transmission electron microscopy (STEM, 200 kV).

\section{Results and Discussion}

\subsection{VFAW and RSW joints}

Fig. 3 shows the specimens after welding; the diameters of the nugget produced for the RSW and VFAW welds in this study were different. The average diameter of the nugget of the VFAW weld was approximately twice that of the RSW nugget size (Fig. 4).

\subsection{Microstructural variations in welds}

The as-received microstructure of the DP 980 grade
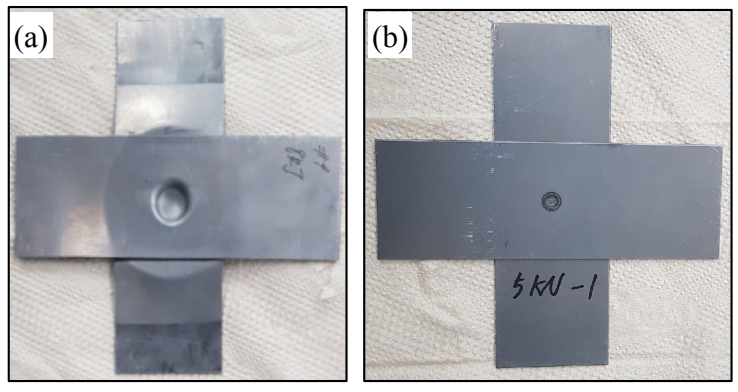

Fig. 3 Photographs of specimens after welding (a) Cross joint of VFAW, (b) Cross joint of RSW 


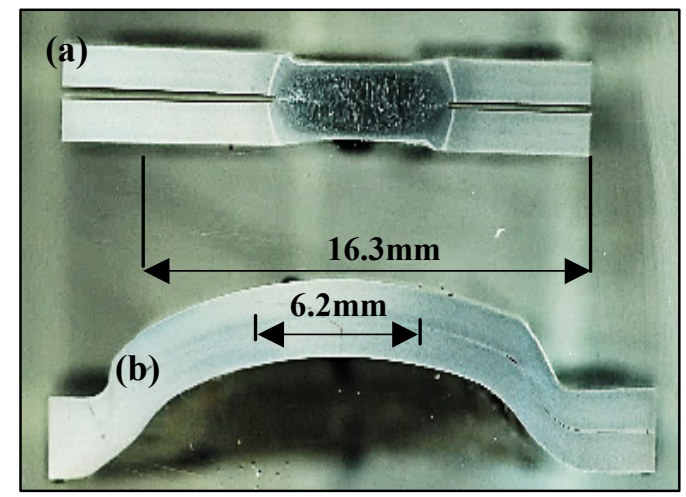

Fig. 4 Comparison of weldments (a) VFAW, (b) RSW

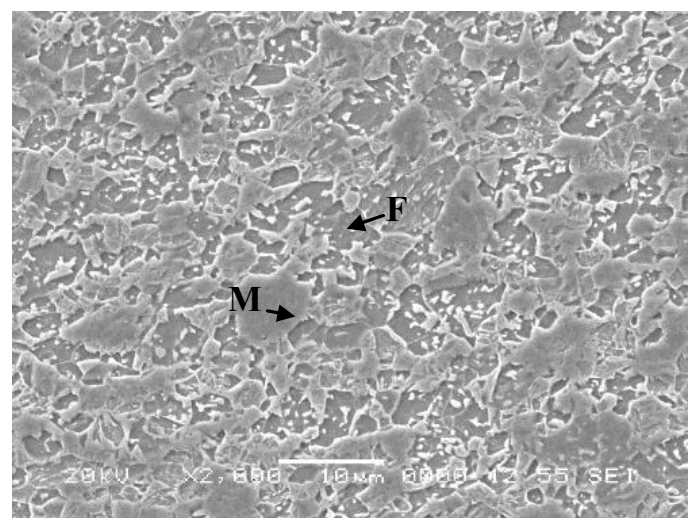

Fig. 5 A typical microstructure of base metal showing a ferrite and martensite

steel consisted of ferrite and martensite is shown in Fig. 5. Some packets of martensite were observed in the block shaped microstructure. This microstructure was mainly resulted from the chemical composition having a high carbon and manganese content ${ }^{1)}$. The fine-grained ferrite matrix containing a large fraction of martensite indicated that the steel experienced a thermo-mechanical processing.

In impact welding, a wavy interface morphology can be observed. The exact mechanism leading to this patterning is still debated to this day ${ }^{14)}$. Some researchers suggest that localized melting and solidification occur at the weld interface ${ }^{8,15,16)}$, while others say that a shear

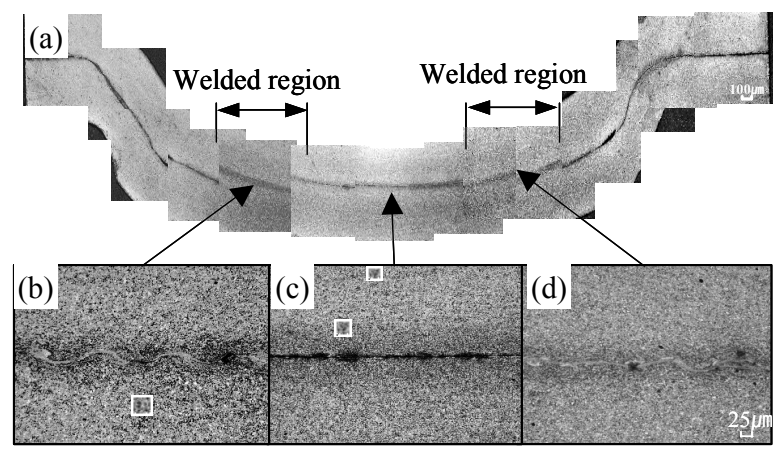

Fig. 6 Optical micrographs showing the weldments of DP980-DP980 VFAW weld (a) Cross section of joint, (b) Welded region, (c) Unwelded region, (d) Welded region

plastic flow instability at the weld interface leads to the wavy pattern ${ }^{17)}$. The sheets welded by VFAW in this study also showed similar characteristics and the presence of a wavy interface was observed (Fig. 6).

Fig. 6 and 7 show the optical micrographs of various locations along the length of the weld for the DP980DP980 VFAW joint. It is known that an impact welded joint consists of an unwelded center region followed by a welded region on both sides. The welded region is then followed by an unwelded region at the end of weld line ${ }^{18)}$. In the case of VFAW welding, the nugget diameter was measured based on the deformation area during welding. These have been marked accordingly in Fig. 4a. Fig. 6b,c,d show the microstructure of the welded and unwelded regions. The hardness values in Fig. 8 indicate that the weld interface is nominally free from any softening. The HAZ of RSW can range from mm to $\mathrm{cm}$ (Fig. 8a), whereas the VFAW joint is completely free from the presence of a HAZ leading to the exceptional strength around the joint perimeter.

Fig. 7 (a) shows the wavy interface of the VFAW weld observed by SEM and EDX analysis result. The width of the deformed zone is around $100 \mu \mathrm{m}$ and more refined grains are observed. Then martensite formed some thin bands (Fig. 7b) and the martensite grew up, eventually forming a thick martensite band (Fig. 7c). In the
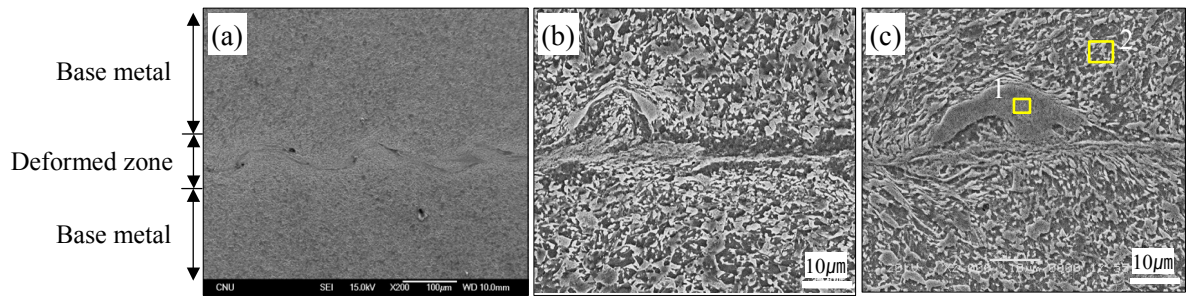

\begin{tabular}{|c|c|c|}
\hline Elements & $\# 1$ & $\# 2$ \\
\hline $\mathrm{Cr} \mathrm{K}$ & 1.03 & 0.99 \\
\hline $\mathrm{Mn} \mathrm{K}$ & 1.61 & 2.61 \\
\hline $\mathrm{Fe} \mathrm{K}$ & 97.35 & 96.39 \\
\hline Totals & 100.00 & 100.00 \\
\hline
\end{tabular}

Fig. 7 SEM microstructure of VFAW (a) Wavy interface, (b) Formation of deformation band, (c) Growth of deformation band 

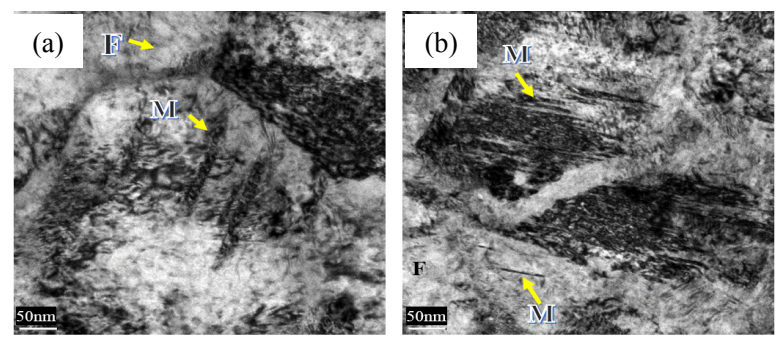

Fig. 8 TEM micrographs showing the weldments of DP980-DP980 VFAW weld (F: ferrite, M: martensite) (a) Base metal, (b) Welded region

martensite band, manganese content was higher than that of matrix.

TEM microstructure of this thick martensite band (Fig. 7c) is displayed at Fig. 8 which shows $\mathrm{M}$ microstructure of base metal and weld region. Fig. 8 (a) shows martensite band in the ferrite grain before the welding whereas after VFAW welding the martensite is surrounded by severely deformed ferrite (Fig. 8 b).

The DP980 base metal reveals about HV 350, while the hardness in the weld interface was increased in the range of HV 400 to 435 . Hardening on the center of the weld occurred on both welding methods but hardness of the VFAW weld was higher than the RSW weld because of the thick martensite band in VFAW weld but there was no HAZ softening in the VFAW weld (Fig. 9, 10).

Fig. 11 illustrates the variation in microstructure across the weldment. Fig. 11 (b) and (c) shows the SEM micrographs of the microstructure of the RSW joint. The locations of FZ, HAZ and BM are schematically showed in the micrographs. The hardness values increase in the fusion zone. The FZ presents a structure that is mostly martensite.

\subsection{Tensile test results}

The tensile test results of DP980-DP980 RSW and

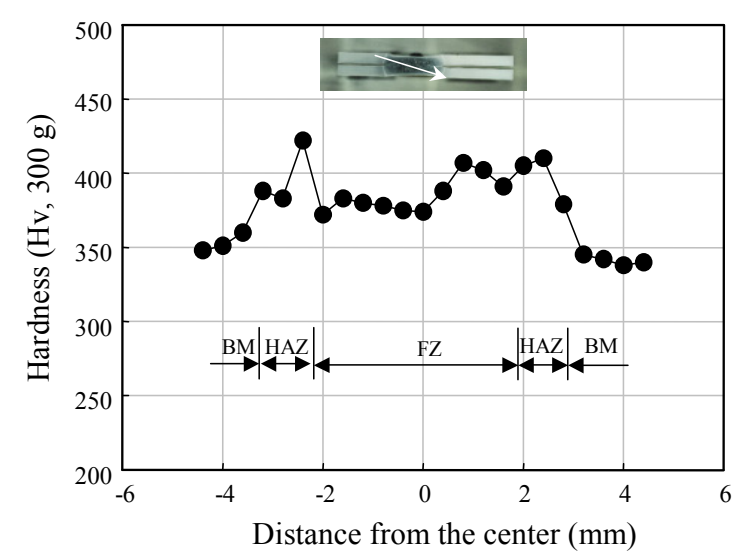

Fig. 9 Distribution of hardness across weldment for RSW weldment
VFAW samples are shown in Fig. 12. The RSW samples failed at $4.8 \mathrm{kN}$. The RSW samples failed when the nugget pulled free from the base metal. The VFAW samples exhibited failure through the weld interface

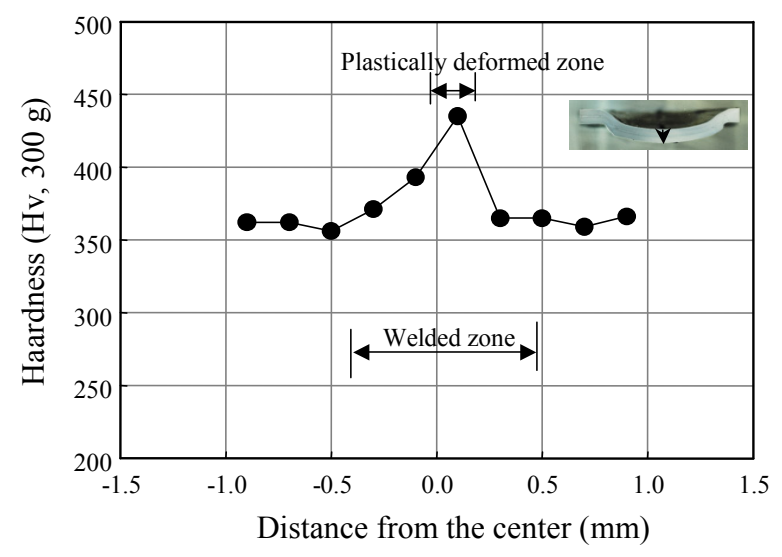

Fig. 10 Distribution of hardness across weldment for VFAW weldment
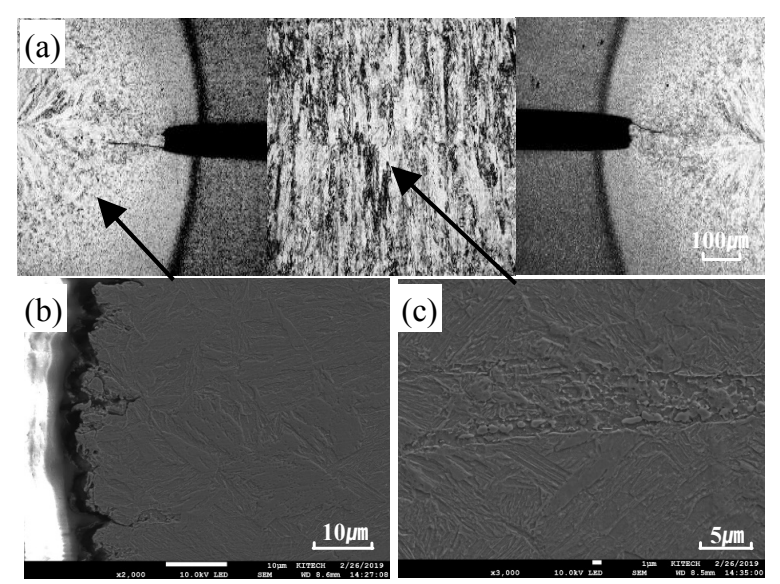

Fig. 11 Optical and SEM microstructure of RSW weld (a) Cross section of weldment, (b) side region, (c) center region

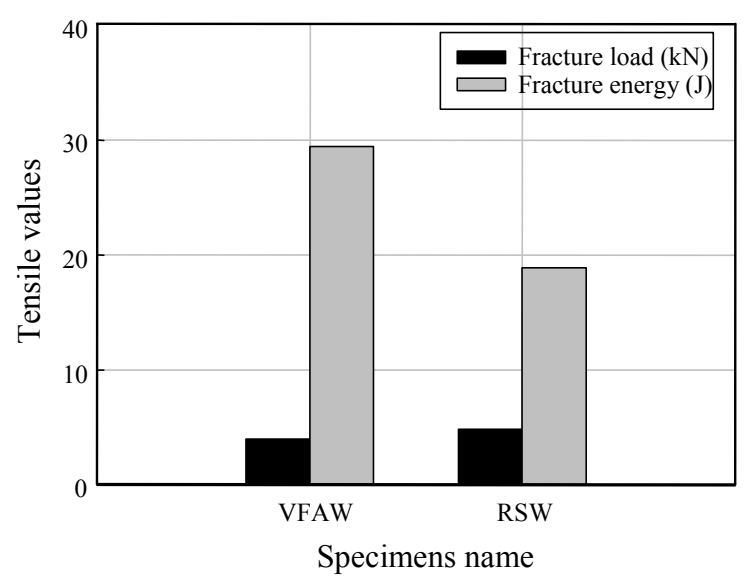

Fig. 12 Cross Tension test results of RSW and VFAW joints 
and failure load $4 \mathrm{kN}$ at cross tension sample. This might have been caused by the differences in bond area around the nugget. It can be observed that the failure loads for cross tension RSW sample was higher than the VFAW cross tension sample.

\subsection{Fracture energy absorption behavior}

The other key metrics obtained from the load-displacement curves were energy absorption and sample elongation. Literature suggests that energy absorption describes spot weld mechanical behavior more precisely; the higher the energy absorption, the higher the weld reliability under impact conditions ${ }^{14)}$. The VFAW samples exhibited higher energy absorption compared to the RSW welds. If the welding conditions of VFAW are further optimized, it is thought that higher tensile values are expected.

\section{Conclusions}

The joint performance of $1 \mathrm{GPa}$ grade steel using vaporizing foil actuator welding process was studied.

The main results are as follows:

1) Welds of DP 980 steels were fabricated by VFAW using 8kJ energy input. Alongside, deformed zone of DP980 by VFAW was very narrow only 100 200 $\mu \mathrm{m}$

2) As a result of the hardness measurement, in RSW occurred HAZ softening and FZ hardening, but in VFAW only hardening occurred in the deformed zone, there was no softening.

3) As a result of microstructure analysis, the fusion zone of RSW was entirely in martensite and the welding zone was created in VFAW, consisting of ferrite and some martensite bands.

\section{Acknowledgements}

"This research was supported by Basic Science Research Program through the National Research Foundation of Korea(NRF) funded by the Ministry of Education (2017R1D1A1B03034324)". The VFAW experimentation was performed at Professor Glenn Daehn's research group at Ohio State University.

ORCID: Byoung-Hyun Yoon: http://orcid.org/0000-0003-4683-7888 ORCID: Taeseon Lee: http://orcid.org/0000-0002-9766-0456

\section{Reference}

1. H. S. Na, J. P. Kong, T. K. Han, K. G. Chin and C. Y. Kang, Hardness Distribution and Microstructures of Electric Resistance Spot Welded 1GPa Grade Dual
Phase Steel, J. Korean Weld. Join. Soc. 30(2) (2012) 180. https://doi.org/10.5781/JWJ.2015.33.6.21

2. D. Y. Choi, Effects of Phosphorus and in-situ Post-heat Pulse Conditions on Resistance Spot Weldability of High Si DP980 Steel Sheet, J. Weld. Join. 33(6) (2015) 21. https://doi.org/10.5781/JWJ.2015.33.6.21

3. G. P. Marques, R. D. S. G. Campilho, F. J. G. da Silva and R. D. F. Moreira, Adhesive selection for hybrid spot-welded/bonded single-lap joints: Experimentation and numerical analysis, Compos. Part B: Eng. 84 (2016) 248.

https://doi.org/10.1016/j.compositesb.2015.09.002

4. C. Y. Choi, D. C. Kim, D. G. Nam, Y. D. Kim and Y. D. Park, A Hybrid Joining Technology for Aluminum/Zinc Coated Steels in Vehicles, J. Mater. Sci. \& Technol. 26 (2010) 858. https://doi.org/10.1016/S1005-0302(10)60137-5

5. J. D. Lee, H. R. Lee, M.S . Kim, J. D. Seo and J. K. Kim, Effect of Weldbond Process on the Weldability of 1.2GPa Grade Galvannealed TRIP Steel for Car Body Manufacturing, J. Weld. Join. 34(6) (2016) 28. https://doi.org/10.5781/JWJ.2016.34.6.28

6. A. Kapil, T. Lee, A. Vivek, J. Bockbrader, T. Abke and G. Daehn, Benchmarking strength and fatigue properties of spot impact welds, J. Mater. Process. Technol. 255 (2018) 219. https://doi.org/10.1016/j.jmatprotec.2017.12.012

7. K. J. Lee, S. Kumai, T. Arai and T. Aizawa, Interfacial microstructure and strength of steel/ aluminum alloy lap joint fabricated by magnetic pressure seam welding, Mater. Sci. and Eng. A 471 (2007) 95. https://doi.org/10.1016/j.msea.2007.04.033

8. A. Ben-Artzy, A. Stern, N. Frage, V. Shribman, O. Sadot, Wave formation mechanism in magnetic pulse welding, Int. J. Impact Eng. 37 (2010) 397. https://doi.org/10.1016/j.ijimpeng.2009.07.008

9. E. P. Carton, Wave Forming Mechanisms in Explosive Welding, Mater. Sci. Forum, 465-466 (2004) 219. https://doi.org/10.4028/www.scientific.net/MSF.465-466.219

10. A. Stern, V. Shribman, A. Ben-Artzy and M. Aizenshtein, Interface Phenomena and Bonding Mechanism in Magnetic Pulse Welding, J. Mater. Eng. Perform. 23 (2014) 3449. https://doi.org/10.1007/s11665-014-1143-0

11. M. Hahn, C. Weddeling, G. Taber, A. Vivek, G. Daehn and A. E. Tekkaya, Vaporizing foil actuator welding as a competing technology tomagnetic pulse welding, J. Mater. Process. Technol. 230 (2016), 8. https://doi.org/10.1016/j.jmatprotec.2015.11.010

12. J. Bellmann, J. Lueg-Althoff, S. Schulze, S. Gies, E. Beyer and A. E. Tekkaya, Effects of Reactive Interlayers in Magnetic Pulse Welding, 8th International Conference on High Speed Forming, Columbus, USA (2018) http://dx.doi.org/10.17877/DE290R-18970 
13. Taeseon Lee, Shunyi Zhang, Anupam Vivek, Glenn Daehn and Brad Kinsey, Wave formation in impact welding: Study of the $\mathrm{Cu}-\mathrm{Ti}$ system, CIRP Annals, 68(1) (2019) 261.

https://doi.org/10.1016/j.cirp.2019.04.058

14. H. W. Lee, C. H. Kim and J. H. Song, An Evaluation of Global and Local Tensile Properties of Friction -Stir Welded DP980 Dual-Phase Steel Joints Using a Digital Image Correlation Method, Mater 8 (2015) 8424. https://doi.org/10.3390/ma8125467

15. A. Kapil, A. Sharma, Magnetic pulse welding: an efficient and environmentally friendly multi-material joining technique, J. Clean. Prod. 100 (2015) 35. https://doi.org/10.1016/j.jclepro.2015.03.042

16. Taeseon Lee, Ali Nassiri, Taylor Dittrich, Anupam Vivek and Glenn Daehn, Microstructure development in impact welding of a model system, Scrip. Mater. 178 (2020) 203. https://doi.org/10.1016/j.scriptamat.2019.11.031

17. I. A. Bataev, D.V. Lazurenko, S. Tanaka, K. Hokamoto, A. A. Bataev, Y. Guo and A. M. Jorge Jr., High cooling rates and metastable phases at the interfaces of explosively welded materials, Acta Mater. 135 (2017) 277. https://doi.org/10.1016/j.actamat.2017.06.038

18. Ali Nassiri, Anupam Vivek, Tim Abke, Bert Liu, Taeseon Lee and Glenn Daehn, Depiction of interfacial morphology in impact welded $\mathrm{Ti} / \mathrm{Cu}$ bimetallic systems using smoothed particle hydrodynamics, Appl. Phys. Lett. 110 (2017) 231601. https://doi.org/10.1063/1.4984742

19. M. I. Khan, M. L. Kuntz and Y. Zhou, Effects of weld microstructure on static and impact performance of resistance spot welded joints in advanced high strength steels, Sci. Technol. Weld. Join. 13 (2008), 294. https://doi.org/10.1179/174329308X271733 